УДК 661.183.2

\title{
ВЛИЯНИЕ ОКИСЛИТЕЛЬНОЙ ОБРАБОТКИ НА СВОЙСТВА УГЛЕРОДНЫХ МАТЕРИАЛОВ ИЗ МИКРОКРИСТАЛЛИЧЕСКОЙ ЦЕЛЛЮЛОЗЫ
}

\author{
(ㄱ) Н.М. Микова ${ }^{* 1}$, И.П. Иванов ${ }^{1}$, Н.В. Чесноков ${ }^{1,2}$, В.Ф. Каргин ${ }^{I}$ \\ ${ }^{1}$ Институт химии и химической технологии СО РАН, Академгородок, 50, \\ Красноярск, 660036 (Россия) \\ ${ }^{2}$ Красноярский научный центр СО РАН, Академгородок, 50, Красноярск, \\ 660036 (Россия), e-mail: nm@icct.ru
}

Модифицирование поверхности карбонизованной при $450{ }^{\circ} \mathrm{C}$ микрокристаллической целлюлозы (МКЦ-450) растворами окисляющих агентов различной силы: $30 \% \mathrm{H}_{2} \mathrm{O}_{2}, 3 \mathrm{~N} \mathrm{H}_{2} \mathrm{SO}_{4}$, олеумом и хлорсульфоновой $\mathrm{HSO}_{3} \mathrm{Cl}$ кислотой приводит к получению углеродных материалов (УМ) с различной степенью окисления поверхности. Полученные УМ были охарактеризованы методами ИК-спектроскопии, БЭТ, элементного и рентгеноспектрального анализа (РСА). Результаты показали, что больше карбоксильных и гидроксильных поверхностных групп вводятся в состав УМ в результате окисления олеумом и $\mathrm{HSO}_{3} \mathrm{Cl}$, чем окисляющими растворами $\mathrm{H}_{2} \mathrm{O}_{2}$ и $3 \mathrm{~N} \mathrm{H}_{2} \mathrm{SO}_{4}$. Установлено, что в образцах МКЦ/олеум и МКЦ/ $\mathrm{HSO}_{3} \mathrm{Cl}$ значительная часть кислорода входит в состав $\mathrm{HSO}_{3}{ }^{-}$поверхностных частиц, содержание серы в которых составляет около 2,3-2,5\% ат. Выяснено, что окисленный образец МКЦ/олеум проявляет активность в тестовых реакциях каталитического гидролиза целлюлозы и этерификации уксусной кислоты с этанолом.

Ключевые слова: микрокристаллическая целлюлоза, карбонизация, окислительная модификация, поверхностные группы, адсорбционные и каталитические свойства.

\section{Введение}

Значительное количество исследований в последние годы сфокусировано на модификации поверхности углеродных материалов окисляющими агентами с целью изучения влияния поверхностных функциональных групп (ФГ) на каталитические и адсорбционные свойства получаемых материалов [1-4]. Важность подобного интереса вытекает из нескольких аспектов: процесс окисления делает возможным фиксацию значительных количеств кислородсодержащих ФГ на поверхности углеродного материала (УМ), усиливая такие специфические характеристики, как гидрофильность, и позволяет минимизировать неорганические примеси в их составе. Поверхностные комплексы оказывают эффективное влияние на направление реакций (в том числе каталитических) с участием углеродной поверхности. Это стимулирует исследования, направленные на по-

Микова Надежда Михайловна - старший научный сотрудник, кандидат химических наук, тел.: (391) 249-53-87, e-mail: nm@icct.ru

Иванов Иван Петрович - старший научный сотрудник, кандидат технических наук, тел.: (391) 249-48-94, e-mail: ivanov@icct.ru

Чесноков Николай Васильевич - заместитель директора Института химии и химической технологии СО РАН, заместитель председателя Красноярского научного центра СО РАН, доктор химических наук, тел.: (391) 249-53-99, e-mail: cnv@ icct.ru Каргин Валерий Федорович - старший научный сотрудник, кандидат химических наук, тел.: (391) 249-55-87, e-mail: kargin@ icct.ru лучение твердокислотных углеродных катализаторов, либо носителей катализаторов, способных заменить используемые в ряде химических технологий жидкофазные катализаторы [5-7].

С целью оптимизации адсорбционных и каталитических свойств, значительные усилия исследователей сосредоточены не только на совершенствовании структурных параметров углеродных материалов, таких как удельная поверхность и распределение пор по размерам, но и на модифицировании химических характеристик (природа и количество поверх-

\footnotetext{
* Автор, с которым следует вести переписку.
} 
ностных ФГ). Модификация поверхности углеродных материалов окисляющими агентами способствует усилению адсорбционной способности по отношению к неорганическим веществам за счет реакций с участием поверхностных кислотных ФГ (фенольных, карбоксильных, гидроксильных и др.) [8-11]. При этом степень окисленности поверхности и реакционно-способность существенным образом зависят как от вида углеродного предшественника, типа окисляющего агента, так и от условий проведения модифицирующего процесса. Поэтому достижение лучшего понимания роли поверхностных ФГ в адсорбционных и каталитических процессах представляется важным.

Цель настоящей работы - изучение влияния условий окислительной модификации углеродных материалов, полученных из карбонизованной микроцеллюлозы, на их адсорбционные и каталитические свойства.

\section{Экспериментальная часть}

В качестве исходного сырья для приготовления углеродного материала использована промышленная (г. Кемерово) микрокристаллическая целлюлоза (МКЦ) с содержанием (вес. \%): С - 48,2; Н - 6,3; $\mathrm{N}-0,15$; $\mathrm{O}$ - 45,35. Карбонизацию МКЦ проводили при температуре $450{ }^{\circ} \mathrm{C}$ со скоростью нагрева $4{ }^{\circ} \mathrm{C} /$ мин в атмосфере аргона и изотермической выдержкой в течение 5 ч. В экспериментах использовали порошок карбонизованной МКЦ фракции 0,2-0,25 мм.

Модифицирующую обработку поверхности исходного карбонизованного углеродного материала (МКЦ-450) осуществляли растворами $30 \% \mathrm{H}_{2} \mathrm{O}_{2}, 3 \mathrm{~N} \mathrm{H}_{2} \mathrm{SO}_{4}$ (100 мл, комнатная температура, 24 ч), олеумом (концентрированная $\mathrm{H}_{2} \mathrm{SO}_{4}+15 \% \mathrm{SO}_{3}$ ) и хлорсульфоновой $\left(\mathrm{HSO}_{3} \mathrm{Cl}\right.$ ) кислотой (нагревание при $80^{\circ} \mathrm{C}, 10$ ч).

В типичном синтезе 6 г образца карбонизованного целлюлозного материала переносили в реакционную колбу объемом 0,25 л. Дымящую серную кислоту с $15 \%$ содержанием $\mathrm{SO}_{3}$ в количестве 100 мл медленно приливали к содержимому колбы и суспензию нагревали при температуре $80^{\circ} \mathrm{C}$ при перемешивании в атмосфере инертного газа в течение 10 ч. Затем реакционную массу охлаждали до комнатной температуры и отфильтровывали. Полученный остаток тщательно промывали горячей дистиллированной водой $\left(\geq 80^{\circ} \mathrm{C}\right)$ до полной отмывки сульфат-ионов $\left(\mathrm{BaCl}_{2}-\right.$ контроль). Полученный углеродный материал (МКЦ/олеум) сушили до постоянного веса при $105-110{ }^{\circ} \mathrm{C}$.

Текстурные и структурные характеристики полученных углеродных материалов изучали с применением анализатора удельной поверхности «Сорбтометр-М».

Микрорентгеноспектральный анализ (РСА) качественного и полуколичественного химического состава углеродных образцов в диапазоне определяемых элементов - от Na (11) до Аm (95) осуществляли в режиме низкого вакуума (до $10^{-6}$ Topp) с использованием кремний-дрейфового детектора TM 3000 EDS с гарантированным разрешением по энергии - 135 эВ. Обработку рентгеновских спектров излучения элементов проводили с использованием программного обеспечения спектрометра. Количественное содержание нормировано к $100 \%$.

Регистрацию ИК-спектров (FTIR) образцов исходной и модифицированной МКЦ осуществляли на ИК-Фурье-спектрометре Vector 22 фирмы Bruker. Съемку спектров стандартизованных навесок образцов производили в таблетках $\mathrm{KBr}$ ( 2 мг в 1000 мг $\mathrm{KBr})$.

Гидролиз порошка микрокристаллической целлюлозы (МКЦ, Германия) осуществляли во вращающемся автоклаве объемом 35 мл при температуре $150^{\circ} \mathrm{C}$, в течение 6 ч. Смесь целлюлозы и твердого катализатора (МКЦ/олеум) в соотношении $1: 1$ помещали в стеклянный реактор и заливали дистиллированной водой. Содержание целлюлозы в воде составляло 40 г/л. Продукты гидролиза целлюлозы анализировали методом газовой хроматографии на пламенно-ионизационном детекторе на хроматографе «VARIAN-450 $\mathrm{GC»} \mathrm{(Нидерланды).} \mathrm{Конверсия} \mathrm{целлюлозы} \mathrm{определялась} \mathrm{весовым} \mathrm{методом} \mathrm{с} \mathrm{точностью} \pm 2-3 \%$.

Элементный анализ основных элементов (C, H, N, S и O) твердых образцов УМ выполнен на прибоpe «Flasch-1000».

Предельную сорбционную способность полученных образцов по воде и бензолу в стационарных условиях равновесного заполнения пор проводили в эксикаторе при комнатной температуре и оценивали весовым методом [12]. 


\section{Обсуждение результатов}

Результаты изучения состава модифицированных образцов МКЦ, полученные на основании проведенного полного элементного анализа (Flash-метод) и полуколичественных оценок методом ренгеноспектрального микроанализа (РСА), представлены в таблице. Согласно полученным различными методами данным, содержание основных элементов в изученных образцах различается. Это объясняется тем, что РСА-анализ дает «завышенные» значения поверхностного кислорода, определяемого в слое толщиной до 3-5 кроме того, учитывает содержание других элементов (H, N) [13].

Сравнение содержания кислорода в объеме и на поверхности окисленных образцов карбонизованной целлюлозы свидетельствует о том, что окисление затрагивает в большей части область углеродной поверхности, чем весь объем, и, по-видимому, ограничивается способностью к проникновению химического реагента внутрь углеродного образца.

На основании проведенных результатов сравнительного элементного состава, данных ИКспектроскопии, а также основываясь на полученных нами ранее РФЭС-исследований [14], можно сделать вывод о высокой степени ароматизации углеродного материала, полученного в результате карбонизации МКЦ при $450{ }^{\circ} \mathrm{C}$ в течение 5 ч. Методом ИКС (рис. 1, кривая 1) в составе образца МКЦ-450 выявлен высокий уровень ОН-функциональных групп различной природы ( 3440 см$\left.{ }^{-1}\right)$ преимущественно в виде фенолов, а также спиртов или алкильных гидроксилов. Углеродный материал из МКЦ обладает небольшим количеством С-Н алифатических частиц (п.п. 2920 и $2853 \mathrm{~cm}^{-1}$ ) и значительным количеством ароматических структур (1600, $\left.3040 \mathrm{~cm}^{-1}\right)$, в том числе полиненасыщенных конденсированных ароматических фрагментов $\left(870,808\right.$ и $\left.746 \mathrm{~cm}^{-1}\right)[14,15]$. Кислород входит преимущественно в состав карбоксильных СООН, карбонильных $\mathrm{C}=\mathrm{O}$ групп ( 1695 $\left.\mathrm{cm}^{-1}\right), \mathrm{C}-\mathrm{O}-\mathrm{C}$ эфирных групп.

Характеристики углеродных материалов из карбонизованной и окисленной различными реагентами МКЦ-450

\begin{tabular}{|c|c|c|c|c|}
\hline Образец & $\begin{array}{c}\text { Содержание C, } \\
\text { PCA/ Flash }\end{array}$ & $\begin{array}{c}\text { Содержание O, PCA/ } \\
\text { Flash }\end{array}$ & $\begin{array}{c}\text { Содержание S, PCA/ } \\
\text { Flash }\end{array}$ & $\mathrm{S}_{\text {БЭТ }}, \mathrm{M}^{2} / \mathrm{I}$ \\
\hline МКЦ-450 & $88,56 / 86,89 *$ & $10,86 / 10,78^{*}$ & - & 26,0 \\
\hline МКЦ-450+30\% $\mathrm{H}_{2} \mathrm{O}_{2}$ & $84,80 / 83,46^{*}$ & $12,83 / 11,87^{*}$ & - & 6,4 \\
\hline МКЦ-450+3 $\mathrm{N} \mathrm{H}_{2} \mathrm{SO}_{4}$ & $83,2 / 80,35^{*}$ & $13,36 / 12,06^{*}$ & $0,59 / 0,38 *$ & 3,8 \\
\hline МКЦ-450+олеум & $74,4 / 73,28^{*}$ & $19,04 / 17,35^{*}$ & $3,07 / 1,85^{*}$ & 18,3 \\
\hline МКЦ-450+ $\mathrm{HSO}_{3} \mathrm{Cl}$ & $74,24 / 72,80^{*}$ & $18,06 / 16,64^{*}$ & $2.23 / 1,55^{*}$ & 12,1 \\
\hline
\end{tabular}

Результаты, полученные РСА (ат. \%) и Flash* (вес. \%) методами.

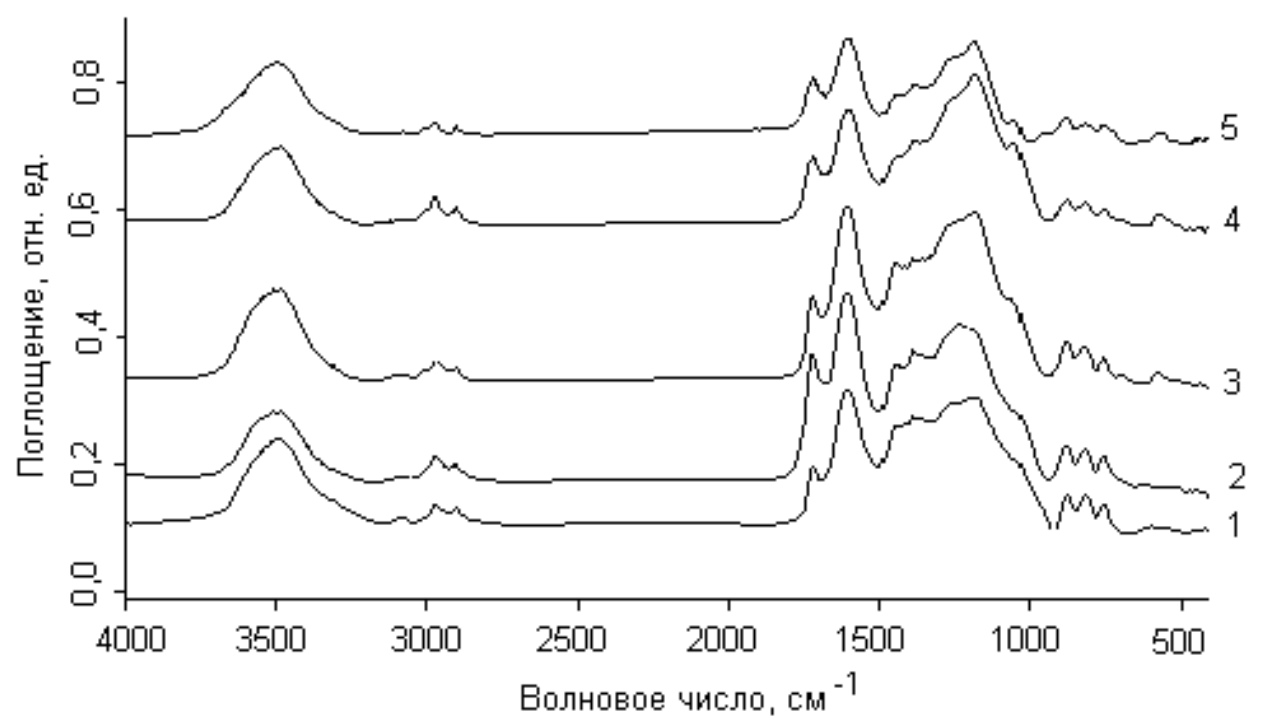

Рис. 1. Кривая 1 - ИК-спектр образца МКЦ-450; кривая 2 - МКЦ+30 \% $\mathrm{H}_{2} \mathrm{O}_{2}$; кривая 3 - МКЦ+ 3N $\mathrm{H}_{2} \mathrm{SO}_{4}$, кривая 4 - МКЦ + олеум, кривая 5 - МКЦ+ $\mathrm{HSO}_{3} \mathrm{Cl}$ 
Известно, что обработка углеродных материалов растворами окисляющих агентов сопровождается окислительными реакциями, приводящими к возрастанию количества О-содержащих групп кислотного типа $[16,17]$. Из сопоставления ИК-спектров различным способом обработанных образцов и из сравнения данных таблицы, становится очевидным, что содержание кислорода, а значит, концентрация кислотных групп в окисленных образцах выше, чем в просто карбонизованном МКЦ. Об этом свидетельствует и усиление поглощения, наблюдаемое вблизи 3400 и около $\sim 1700 \mathrm{~cm}^{-1}$, главным образом за счет $\mathrm{OH}-$ и $\mathrm{C}=\mathrm{O}$ колебаний связей в карбоксильных С(О)ОН группах $[17,21]$. Спектры образцов показывают близкое подобие, подтверждая, что они обладают схожими ФГ, хотя и с различающейся степенью модифицирования поверхности $[2,13,18,19]$.

«Мягкое» окисление растворами пероксида водорода и разбавленной $\mathrm{H}_{2} \mathrm{SO}_{4}$ приводит к незначительному снижению количества углерода и умеренному повышению общего содержания кислорода. На поверхности модифицированных олеумом и хлорсульфоновой кислотами образцов, согласно РСА, генерируется большее содержание кислорода (18-19 ат. \%), чем окисляющими растворами $\mathrm{H}_{2} \mathrm{O}_{2}$ и $3 \mathrm{~N}_{2} \mathrm{SO}_{4}$ (11-12 ат.\%). С возрастанием силы окислительного воздействия в ряду: $\mathrm{H}_{2} \mathrm{O}_{2} \leq 3 \mathrm{~N} \mathrm{H}_{2} \mathrm{SO}_{4}<$ олеум $\sim \mathrm{HSO}_{3} \mathrm{Cl}$ содержание поверхностного кислорода в углеродных образцах возрастает.

В результате окислительных процедур методами ИК- и РФЭ-спектроскопии в модифицированных растворами $30 \% \mathrm{H}_{2} \mathrm{O}_{2}$ и $3 \mathrm{~N} \mathrm{H}_{2} \mathrm{SO}_{4}$ образцах МКЦ выявлено умеренное усиление концентрации карбоксильных $\left(-\mathrm{CO}_{2} \mathrm{H}\right)$ и эфирных/гидроксильных групп. Установлено, что в образцах МКЦ/олеум и $\mathrm{MKЦ/} / \mathrm{HSO}_{3} \mathrm{Cl}$ значительная часть кислорода также входит в состав $\mathrm{HSO}_{3}{ }^{-}$поверхностных частиц, предположительно связанных с ароматическими углеродными атомами. Для МКЦ/3 $\mathrm{NH}_{2} \mathrm{SO}_{4}$ также не исключается наличие сильно адсорбированных молекул воды и/или гидратированных $\mathrm{SO}_{4}^{-}$анионов [14, 20]. По данным полуколичественной оценки элементного состава образцов методом РСА, содержание серы в составе $\mathrm{R}-\mathrm{SO}_{2}-\mathrm{OH}$ сульфокислот в поверхностном слое окисленного $3 \mathrm{~N}$ раствором $\mathrm{H}_{2} \mathrm{SO}_{4}$ углеродного об-

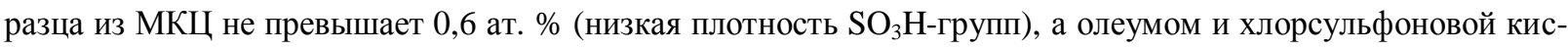
лотами составляет около 2,2-3,0 ат.\% соответственно. Из совокупности полученных данных следует, что общее количество О-поверхностных групп, в частности карбоксильных, при модификации углеродной поверхности олеумом и хлорсульфоновой кислотами возрастает значительней по сравнению с действием разбавленной серной кислоты или пероксидом водорода.

Окисление твердых углеродных материалов, содержащих связанные с ароматическими циклами функциональные группы, в некоторой степени является аналогичным окислению ароматических углеводородов [21]. Поэтому можно ожидать реакции, которые происходят с ароматическими углеводородами, вероятно, применимы и к углеродным материалам. Алифатические молекулярные цепочки, играющие роль сшивки между полиароматическими звеньями, восприимчивы к действию сильных окислителей, таких как олеум и хлорсульфоновая кислота, поэтому конечными продуктами окисления могут быть арилкарбоксильные кислоты. Поверхностные функциональные группы (карбоксильные, фенольные и др.) в окисленных углеродных материалах являются аналогичными группам в ароматических карбоксильных кислотах и фенолах. Помимо гидроксильных $-\mathrm{C}-\mathrm{OH}$, карбонильных $-\mathrm{C}=\mathrm{O}$ и карбоксильных $-\mathrm{COOH}$ кислотных групп, окислительная модификация может увеличивать концентрацию других О-содержащих ФГ, таких как ангидриды, простые и сложные эфиры, лактоны, а также S-содержащих частиц.

Одновременно в результате окислительных обработок изменяются значения удельной поверхности

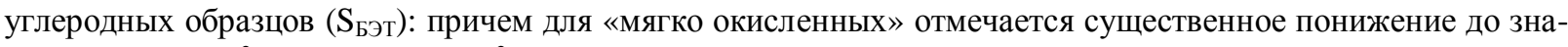
чений $3,8-6,4 \mathrm{~m}^{2} / \Gamma$ против $26,0 \mathrm{~m}^{2} / \Gamma$ - для неокисленной МКЦ. Вероятной причиной снижения могут являться гуминовые вещества - побочные продукты окислительного процесса, блокирующие поры, полнота удаления которых не может гарантироваться промыванием только дистиллированной водой [21]. Сильные окисляющие агенты способны нарушать пористую структуру углеродного материала, в том числе за счет

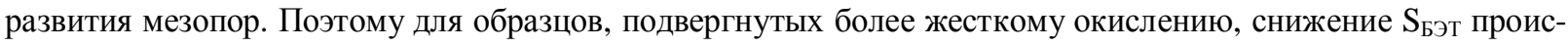
ходит в меньшей степени ( 12-18 м²/г) за счет частичного изменения в структуре, расслоения и разрыхления поверхности. По мере того, как степень окислительного воздействия прогрессирует, большее количество О-содержащих групп добавляется в ходе синтеза не только к внешней, но и к внутренней поверхности углеродного образца [19].

Очевидно, что сила кислородных поверхностных функциональных групп, их гидрофильность, роль в качестве поверхностных оксидных центров может оказывать существенное влияние на адсорбционные процессы с участием этих углеродных адсорбентов. 
Модифицированная поверхность углеродного адсорбента является гетерогенной, имеющей гидрофобную область (чисто углеродную) и полярные функциональные группы. Реализация эффекта модельных адсорбатов близкого молекулярного размера, но различной полярности была использована на примере сорбции $\mathrm{H}_{2} \mathrm{O}$ и бензола, чтобы охарактеризовать влияние поверхностных групп на сорбционную активность УМ. Установлено, что окисленные углеродные материалы, приготовленные на основе карбонизованной МКЦ, способны включать большое количество воды во внутренний объем (до 0,5-0,9 г/г), и чем жестче условия окисления, тем заметнее склонность к адсорбции паров $\mathrm{H}_{2} \mathrm{O}$ за счет роста поверхностной концентрации центров взаимодействия. Из показателей относительно невысоких значений удельной поверхности $\left(\mathrm{S}_{\text {Бэт }} 4-18 \mathrm{~m}^{2} / \Gamma\right)$ при сорбции $\mathrm{N}_{2}$ молекул можно предположить ограниченный уровень развития пористости в окисленных образцах. Однако, в том числе, за счет развития мезопористости обеспечивается доступ молекул $\mathrm{H}_{2} \mathrm{O}$ к полярным кислотным центрам сорбента, способствующий их связыванию с адсорбционными поверхностными атомами.

Адсорбция воды реализуется за счет образования водородных связей как между кислородными комплексами на поверхности углеродного адсорбента (первичные центры адсорбции), так и между адсорбированными молекулами (вторичными центрами). Вода взаимодействует с гидрофильными центрами, которыми могут являться кислородные атомы различных поверхностных групп, связанных с углеродной матрицей [22]. Увеличение содержания О-содержащих кислотных групп приводит к повышению сорбционной емкости сорбентов молекул воды за счет образования Н-связей, в том числе хемосорбционных взаимодействий $[23,24]$.

Выявлена отличительная особенность окисленных производных МКЦ к усилению поглотительной активности от продолжительности процесса сорбции в атмосфере насыщенных паров воды. Для исходного карбонизованного образца МКЦ она стабилизируется в течение 1-3 сут., а для карбонизованной МКЦ модифицированной $\mathrm{H}_{2} \mathrm{O}_{2}$ - через 5 сут. Как видно из рисунка 2, сорбенты, полученные из МКЦ, обработанных разбавленной и дымящей $\mathrm{H}_{2} \mathrm{SO}_{4}$ и $\mathrm{HSO}_{3} \mathrm{Cl}$ кислотами характеризуются тенденцией повышения сорбционной емкости в течение 10-25 сут. выдержки.

Усиление адсорбционной активности, видимо, происходит из-за возрастания числа центров, вовлеченных в адсорбционный процесс, в соответствии с широко принятой концепцией вероятного механизма адсорбции $\mathrm{H}_{2} \mathrm{O}$. Он включает следующие стадии:

а) адсорбцию на поверхности функциональных групп;

б) адсорбцию воды на уже предварительно адсорбированных молекулах $\mathrm{H}_{2} \mathrm{O}$ с образованием водородных связей типа $\mathrm{H}_{2} \mathrm{O} \cdots \mathrm{H} \cdots \mathrm{OH}_{2}$ между молекулами воды и протонами поверхностных кислотных групп (кластеров воды);

в) последующую миграцию и объемного заполнения пор с выходом на плато [25, 26].

Подвижность полиароматического углеродного каркаса, несущего на своей поверхности кислотные ФГ, позволяет адсорбировать значительные количества $\mathrm{H}_{2} \mathrm{O}$ подобно ионообменным смолам, не только на поверхности, но и в объеме [5].

Поверхностная химия углеродных адсорбентов играет важную роль в случае сорбции полярных веществ, в то время как их пористость приобретает большее значение в процессах сорбции неполярные соединений. Это находит подтверждение в том, что молекулы воды и бензола адсорбируются на различных местах углеродной поверхности [26]. Было выявлено, что склонность к образованию кислородных комплексов на углеродной поверхности при взаимодействии кислотных ФГ с молекулами воды возрастает на фоне значительного снижения их способности к физической сорбции бензола. Проведенные сравнительные измерения адсорбции бензола на углеродных образцах показали, что имеющий самую низкую степень окисления МКЦ $/ \mathrm{H}_{2} \mathrm{O}_{2}$ и немодифицированная карбонизованная МКЦ имеют сходные значения сорбционной активности и по воде, и по бензолу, так как молекулы этих веществ способны сорбироваться в порах близкого размера ( $\leq 2 \mathrm{Hм})$.

В данном случае, по-видимому, определяющей является роль физических факторов: пористая структура адсорбента (размер и число микропор) и, в частности, невысокая степень поляризации углеродной поверхности. Тот факт, что по истечении 10 сут. контакта не подвергнутый окислительному воздействию углеродный образец МКЦ продолжает поглощать бензол лучше, чем воду, указывает на то, что процесс сорбции является более чувствительным к размеру (и, возможно, форме) пор, чем к природе поверхностных кислородсодержащих групп. 


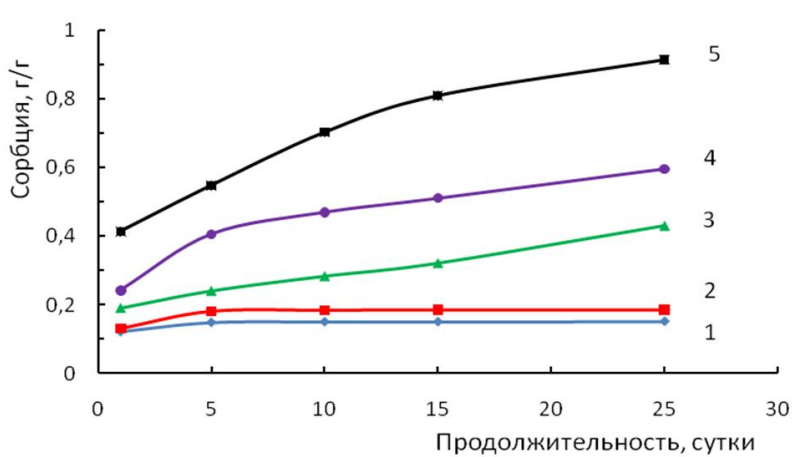

Рис. 2. Динамика сорбции паров воды от времени на образцах: 1 - МКЦ-450, исх; 2 - МКЦ-450/ 30\% $\mathrm{H}_{2} \mathrm{O}_{2} ; 3$ - МКЦ $3 \mathrm{~N} \mathrm{H}_{2} \mathrm{SO}_{4}, 4$ - МКЦ олеум; $5-\mathrm{MKЦ} \mathrm{HSO}_{3} \mathrm{Cl}$

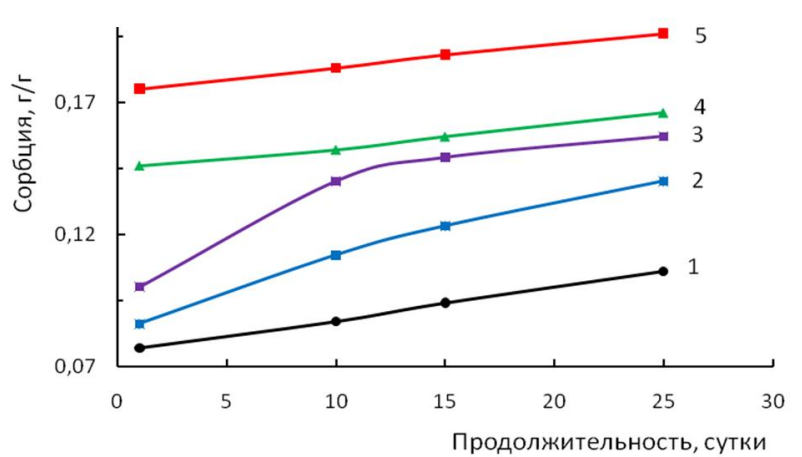

Рис. 3. Динамика сорбции паров бензола на образцах: 1 - МКЦ олеум; 2 - МКЦ $\mathrm{HSO}_{3} \mathrm{Cl}$; 3 - МКЦ $3 \mathrm{~N} \mathrm{H}_{2} \mathrm{SO}_{4} ; 4-30 \% \mathrm{H}_{2} \mathrm{O}_{2} ; 5$ - МКЦ-450 исх.

Из анализа сравниваемых рисунков 2 и 3 становится очевидным, что адсорбция бензола на окисленных и сульфатированных образцах затруднена. Присутствие гетерогенных поверхностных мест, в частности кислородсодержащих групп, оказывает влияние на адсорбционную способность бензола, несмотря на то, что кислотные группы составляют незначительную часть от общей поверхности. Для гидрофобного ароматического соединения, каким является бензол, снижение адсорбционной активности напрямую связано с увеличением числа ФГ кислотного типа и полярностью поверхности. Другим возможным фактором, влияющим на снижение адсорбционной активности молекул бензола, может являться отсутствие эффекта локализации электронов поверхностными группами, что приводит к устранению дисперсионных взаимодействий с ароматическим соединением [26].

Большую склонность к сорбции бензола среди производных МКЦ, содержащих сульфогруппу, проявляет образец МКЦ/3N $\mathrm{H}_{2} \mathrm{SO}_{4}$, что объясняется относительно невысоким содержанием кислородсодержащих групп и слабой полярностью поверхности в целом. Согласно полученным данным по сорбции паров

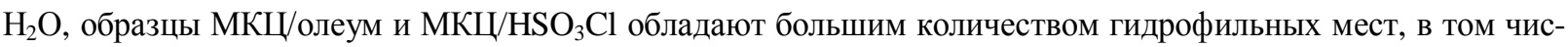
ле $\mathrm{HSO}_{3}$-группами: усиление сорбции $\mathrm{H}_{2} \mathrm{O}$ в 5,6-6,5 раз превышает сорбцию бензола даже по истечении 25 дней контакта. Можно считать, что это происходит за счет вклада хемосорбции воды, обусловленного образованием поверхностных комплексов и проявляющегося в виде образования прочных связей, главным образом с относительно сильнокислотными карбоксильными - $\mathrm{COOH}$ и $\mathrm{HSO}_{3}$-группами.

Эффективность проникновения паров воды во внутренние области углеродной матрицы может служить качественной мерой способности окисленного углеродного материала к каталитическому действию в гидролитических реакциях с участием воды или водных растворов.

Каталитическое поведение сульфатированной олеумом карбонизованной МКЦ изучено в тестовой реакции этерификации уксусной кислоты с этанолом $[5,27]$. Для проведения реакции использовали 0,2 г катализатора, предварительно вакуумированного при $100{ }^{\circ} \mathrm{C}$ в течение 1 ч, со смесью $\mathrm{C}_{2} \mathrm{H}_{5} \mathrm{OH}(1$ моль) и $\mathrm{CH}_{3} \mathrm{COOH}\left(0,1\right.$ моль) при $70{ }^{\circ} \mathrm{C}$ в атмосфере Ar. В ходе реакции жидкая фаза анализировалась на газовом хроматографе с капиллярной колонкой. Проведенными исследованиями было установлено, что уже через 0,5 ч в реакционной смеси присутствует до 7,6 об. \% этилового эфира уксусной кислоты $\mathrm{CH}_{3} \mathrm{CO}_{-} \mathrm{OC}_{2} \mathrm{H}_{5}$.

Результаты газохроматографического исследования, представленные на рисунке 4, показали, что количество образующегося этилацетата (ЭА) в реакционной смеси растет в течение первого часа, достигая своего максимума ( 16 об. \%) через 2 ч от начала реакции, когда вся уксусная кислота оказывается превращенной. Экспериментально подтверждено, что ЭА является единственным хроматографически регистрируемым продуктом реакции (наряду с определяемым этанолом, заведомо взятым в избыточном количестве).

В соответствии с описанной в $[7,28]$ методикой применения углеродных сульфированных материалов в качестве твердокислотных катализаторов реакции гидролиза натуральных углеводов, каталитическое поведение образца МКЦолеум испытано на модельной реакции гидролиза сахарозы в моносахариды. Каталитическое действие углеродного катализатора МКЦ / олеум (0,5 г) проявлялось в гидролитическом превращении микрокристаллической целлюлозы (0,45 г) в водной среде (11 г) до водорастворимых мономеров (глюкозы, ксилозы). В результате гидролитическая конверсия МКЦ в ксилозу и глюкозу составила 28 вес. \% с выходом мономеров 0,850 и 1,004 мг/мл соответственно. 
Рис. 4 . Зависимость выхода этилацетата от продолжительности реакции этерификации уксусной кислоты этанолом на углеродном катализаторе МКЦ/олеум

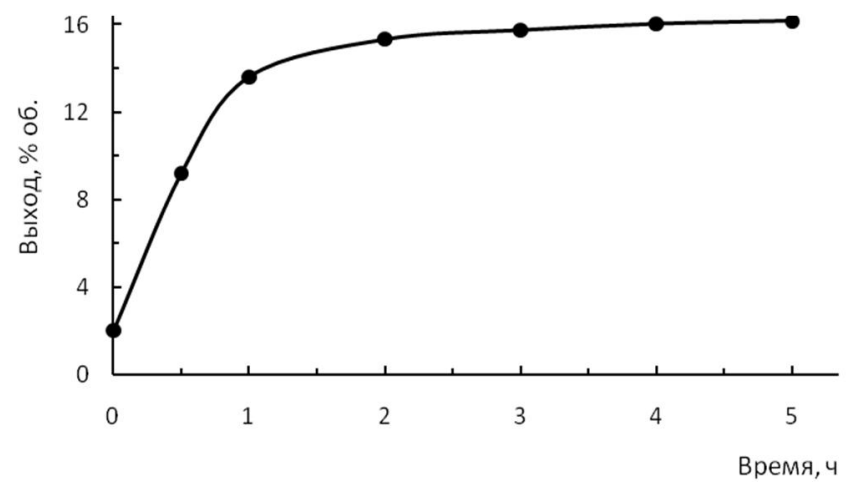

\section{Заключение}

Таким образом, варьированием модифицирующих обработок с применением окисляющих агентов различной силы и природы был приготовлен ряд углеродных адсорбентов и катализаторов на основе карбонизованной МКЦ с различающейся степенью окисления поверхности. Методами элементного и ренгеноспектрального анализов, ИК-, РФЭ-спектроскопии показано, что в результате процесса окисления олеумом (концентрированная $\mathrm{H}_{2} \mathrm{SO}_{4}+15 \% \mathrm{SO}_{3}$ ) и хлорсульфоновой $\mathrm{HSO}_{3} \mathrm{Cl}$ кислотами возможно осуществлять внедрение дополнительного количества кислородсодержащих (главным образом карбоксильных) и сульфогрупп на поверхность образца.

Показано, что адсорбционные свойства полученных углеродных материалов определяются в значительной мере типом, количеством и силой связывания поверхностных функциональных групп, которые, в свою очередь, определяются условиями приготовления и типом окислительной модификации и выбором адсорбата. Установлено, что высококислотные поверхностные группы способны образовывать сильные взаимодействия с молекулами воды, удерживая до 0,7-0,9 г/г.

Выяснено, что характер взаимодействия окисленный углеродный адсорбент - бензол значительно снижается, вплоть до слабого взаимодействия $(\leq 0,01$ г/г), тем самым во влажных условиях применения углеродных адсорбентов они могут выступать в роли щита для проникновения неполярных органических веществ - адсорбатов.

На основании полученных результатов можно предположить способ получения из доступного лигноцеллюлозного источника углеродных материалов со стабильными и каталитически активными поверхностными функциональными группами. Получение углеродных материалов может быть расширено для их применения в качестве катализаторов реакций кислотно-каталитических превращений растительного сырья. Возможная реализация условий повышения содержания кислотных групп на поверхности карбонизованной МКЦ позволит интенсифицировать процесс каталитического гидролиза целлюлозы.

\section{Список литературы}

1. Langley L., Villanueva D., Fairbrother D. Quantification of surface oxides on carbonaceous materials // Chem. Mat. 2006. Vol. 18. N1. Pp. 169-178.

2. Moreno-Castilla C., Lopez-Ramon M.V., Carrasco-Marin F. Changes in surface chemistry of activated carbon by wet oxidation // Carbon. 2000. Vol. 38. N14. Pp. 1995-2001.

3. Vinke P., Eijk van der M., Verbree M., Voskamp A.F., Bekkum van H. Modification of the surfaces of gas-active carbon and a chemically active carbon with nitric acid, hypochlorite, and ammonia // Carbon. 1994. Vol. 32 . N4. Pp. 675-686.

4. Corapcioglu M.O., Huang C.P. The surface acidity and characterization of some commercial active carbons // Carbon. 1987. Vol. 25, N4. Pp. 569-578.

5. Okamura M., Takagaki A., Toda M., Kondo J.N., Domen K., Tatsumi T., Hara M. Acide-catalyzed reactions on flexible polycyclic aromatic carbon in amorphous carbon // Chem. Mater. 2006. Vol. 18. N13. Pp. 3039-3045.

6. Stijn Van de Vyver, Li Peng, Jan Geboers at al. Sulfonated silica/carbon nanocomposites as novel catalysts for hydrolysis of cellulose to glucose // Green Chem. 2010. Vol. 12. Pp. 1560-1563.

7. Onda A., Ochi T., Yanagisawa K. Selective hydrolysis of cellulose into glucose over solid acid catalysts // Green Chem. 2008. Vol. 10, N10. Pp. 1033-1037. 
8. Chen J.P., Wu S., Chongs K. Surface modification of a granular activated carbon by citric acid for enhancement of copper adsorption // Carbon. 2003. Vol. 41. Pp. 1979-1986.

9. Mugisidi D., Ranaldo A., Soedarsono J.W., Hikam M. Modification of activated carbon using sodium acetate and its regeneration using sodium hydroxide for the adsorption of copper from aqeous solution // Carbon. 2007. Vol. 45. Pp. 1081-1084.

10. Santiago M., Stuber F., Fabregat A., Font J. Modified activated carbons for catalytic wet air oxidation of phenol // Carbon. 2005. Vol. 43. N10. Pp. 2334-2345.

11. Chen J.P., Wu S.N. Acid/base-treated activated carbons: characterization of functional groups and metal adsorptive properties // Langmuir. 2004. Vol. 20. N6. Pp. 2233-2242.

12. Park S.J., Kim K.D. Influence of activation temperature on adsorption characteristics of activated fiber composites // Carbon. 2001. Vol. 39. N11. Pp. 1741-1746.

13. Beck N.V., Meech S.E., Norman P.R., Pears L.A. Characterization of surface oxides on carbon and their influence on dynamic adsorption // Carbon. 2002. Vol. 40. Pp. 531-540.

14. Микова Н.М., Чесноков Н.В., Иванов И.П., Михлин Ю.Л., Кузнецов Б.Н. Изучение свойств углеродных материалов, модифицированных кислотами // Техническая химия от теории к практике : сб. труд. III Междун. конф. Пермь, 2012. С. 245-249.

15. Abdel-Nasser A,. El-Hendawy. Variation in the FTIR spectra of biomass under impregnation, carbonization and oxidation conditions // J. Anal. Appl. Pyrolysis. 2006. Vol. 75. Pp. 159-166.

16. Berenguer R., Marco-Lozar J.P., Quijada C., Cazorla-Amoros D., Morallon E. A comparision between oxidation of activated carbon by electrochemical and chemical treatments // Carbon. 2012. Vol. 50. Pp. 1123-1134.

17. Langley L.A., Fairbrother D.H. Effect of wet chemical treatments on the distribution of surface oxides on carbonaceous materials // Carbon. 2007. Vol. 45. Pp. 47-54.

18. Pradhan K.B., Sandle K.N. Effect of different agent treatments on the surface properties of activated carbons // Carbon. 1999. Vol. 37. Pp. 1323-1332.

19. Adams L.B., Hall C.R., Holmes R.J., Newton R.A. An examination of how exposure to humid air can result in changes in the adsorption properties of activated carbon // Carbon. 1998. Vol. 26, N4. Pp. 451-459.

20. Mazov I., Kuznetsov V.L., Simonova I.A., Stadnichenko A.I., Ishchenko A.V., A.V., Romanenko A.I., Tkachev E.N., Anikeeva O.B. Oxidation behavior of multiwall carbon nanotubes with different diameters and morphology // Applied Surface Science. 2012. Vol. 258. Pp. 6272-6280.

21. Chingombe P., Saha B., Wakeman R.J. Surface modification and characterization of coal-based activated carbon // Carbon. 2005. Vol. 43. Pp. 3132-3143.

22. Groszek A. Graphitic and polar surface sites in carbonaceous solids // Carbon. 1987. Vol. 25. N6. Pp. 717-722.

23. Strelko Jr.V., Malik D.J., Streat M. Characterization of the surface of oxidized carbon adsorbents // Carbon. 2002. Vol. 40. Pp. 95-104.

24. Грег С., Синг Л. Адсорбция, удельная поверхность, пористость. М., 1984. 306 с.

25. Pastor-Villegas J., Meneses Rodriguez J.M., Pastor-Valle J.F., Garcia Garcia M. Changes in commercial wood charcoals by thermal treatments // J. Anal. Appl. Pyrolysis. 2007. Vol. 80. Pp. 507-514.

26. Rodriguez-Mirasol J., Bedia J., Cordero T. Influence of water vapor on the adsorption of VOGs on lignin-based activated carbons // Separation Science and Technology. 2005. Vol. 40. Pp. 3113-3135.

27. Hara M., Yoshida T., Takagaki A., Takata T., Kondo J.N., Hayashi Sh., Domen K. A carbon material as a strong protonic acide // Angew. Chem. Int. Ed. 2004. Vol. 43. Pp. 2955-2958.

28. Suganuma S., Nakajima K., Kitano M., Amaguchi D.Y., Kato H., Hayashi Sh., Hara M. Hydrolysis of Cellulose by Amorphous Carbon Bearing $\mathrm{SO}_{3} \mathrm{H}, \mathrm{COOH}$, and $\mathrm{OH}$ Groups // Am. Chem. Soc. 2008. Vol. 130, N38. Pp. 12787-12793. 
Mikova N.M. ${ }^{{ }^{*},}$, Ivanov I.P. ${ }^{l}$, Chesnokov N.V. ${ }^{1,2}$, Kargin V.F. ${ }^{l}$ THE OXIDATIVE TREATMENT INFLUENCE ON THE PROPERTIES OF CARBON MATERIALS OBTAINED FROM MICROCRYSTAL CELLULOSE

${ }^{I}$ Institute of Chemistry and Chemical Technology SB RAS, Krasnoyarsk (Russia)

${ }^{2}$ Krasnoyarsk Scientific Centre SB RAS, Akademgorodok, 50, Krasnoyarsk, 660036, (Russia), e-mail: cnv@icct.ru

The surface modification of carbonized at $450{ }^{\circ} \mathrm{C}$ microcrystal cellulose (MCC-450) by the oxidative agents solutions of different strength: $30 \% \mathrm{H}_{2} \mathrm{O}_{2}, 3 \mathrm{~N} \mathrm{H}_{2} \mathrm{SO}_{4}$, oleum and chlorosulfonic acid $\mathrm{HSO}_{3} \mathrm{Cl}$ results in preparation of carbon materials (CM) with different degrees of surface oxidation. The obtained CM were characterized using FTIR, BET, elemental and X-ray spectral analyses. The obtained results showed that more carboxylic and hydroxyl surface oxygen groups were introduced into $\mathrm{CM}$ composition as a result of oleum and $\mathrm{HSO} 3 \mathrm{Cl}$ oxidation process than by the oxidative solutions of $\mathrm{H}_{2} \mathrm{O}_{2}$ и $3 \mathrm{~N} \mathrm{H}_{2} \mathrm{SO}_{4}$. Significant quality of surface oxygen in the $\mathrm{MCC} /$ oleum and $\mathrm{MCC} / \mathrm{HSO}_{3} \mathrm{Cl}$ samples is part of $\mathrm{HSO}_{3}{ }^{-}$groups, where the $\mathrm{S}$ content was 2,3-2,5\% at. It has been found that oxidized sample $\mathrm{MCC} /$ oleum reveals activity in test reactions of cellulose catalytic hydrolysis and esterification of acetic acid with ethanol.

Keywords: microcrystal cellulose, carbonization, oxidative modification, surface groups, adsorption and catalytic properties.

\section{References}

1. Langley L., Villanueva D., Fairbrother D. Chem. Mat., 2006, Vol. 18, no. 1, pp. 169-178.

2. Moreno-Castilla C., Lopez-Ramon M.V., Carrasco-Marin F. Carbon, 2000, vol. 38, no. 14, pp. 1995-2001.

3. Vinke P., Eijk van der M., Verbree M., Voskamp A.F., Bekkum van H. Carbon, 1994, vol. 32, no. 4, pp. $675-686$.

4. Corapcioglu M.O., Huang C.P. Carbon, 1987, vol. 25, N4, pp. 569-578.

5. Okamura M., Takagaki A., Toda M., Kondo J.N., Domen K., Tatsumi T., Hara M. Chem. Mater., 2006, vol. 18, no. 13, pp. 3039-3045.

6. Stijn Van de Vyver, Li Peng, Jan Geboers at al. Green Chem., 2010, vol. 12, pp. 1560-1563.

7. Onda A., Ochi T., Yanagisawa K. Green Chem., 2008, vol. 10, N10, pp. 1033-1037.

8. Chen J.P., Wu S., Chongs K. Carbon, 2003, vol. 41, pp. 1979-1986.

9. Mugisidi D., Ranaldo A., Soedarsono J.W., Hikam M. Carbon, 2007, vol. 45, pp. 1081-1084.

10. Santiago M., Stuber F., Fabregat A., Font J. Carbon, 2005, vol. 43, no. 10, pp. 2334-2345.

11. Chen J.P., Wu S.N. Langmuir, 2004, vol. 20, no. 6, pp. 2233-2242.

12. Park S.J., Kim K.D. Carbon, 2001, vol. 39, no. 11, pp. 1741-1746.

13. Beck N.V., Meech S.E., Norman P.R., Pears L.A. Carbon, 2002, vol. 40, pp. 531-540.

14. Mikova N.M., Chesnokov N.V., Ivanov I.P., Mikhlin Iu.L., Kuznetsov B.N. Tekhnicheskaia khimiia ot teorii $k$ praktike: sb. trud. III mezhdun. konf. [Technical chemistry from theory to practice: Proceedings of the III International Conference]. Perm, 2012, pp. 245-249. (in Russ.).

15. Abdel-Nasser A,. El-Hendawy. J. Anal. Appl. Pyrolysis, 2006, vol. 75, pp. 159-166.

16. Berenguer R., Marco-Lozar J.P., Quijada C., Cazorla-Amoros D., Morallon E. Carbon, 2012, vol. 50, pp. $1123-1134$.

17. Langley L.A., Fairbrother D.H. Carbon, 2007, vol. 45, pp. 47-54.

18. Pradhan K.B., Sandle K.N. Carbon, 1999, vol. 37, pp. 1323-1332.

19. Adams L.B., Hall C.R., Holmes R.J., Newton R.A. Carbon, 1998, vol. 26, no. 4, pp. 451-459.

20. Mazov I., Kuznetsov V.L., Simonova I.A., Stadnichenko A.I., Ishchenko A.V., A.V., Romanenko A.I., Tkachev E.N., Anikeeva O.B. Applied Surface Science, 2012, vol. 258, pp. 6272-6280.

21. Chingombe P., Saha B., Wakeman R.J. Carbon, 2005, vol. 43, pp. 3132-3143.

22. Groszek A. Carbon, 1987, vol. 25, no. 6, pp. 717-722.

23. Strelko Jr.V., Malik D.J., Streat M. Carbon, 2002, vol. 40, pp. 95-104.

24. Greg S., Sing L. Adsorbtsiia, udel'naia poverkhnost', poristost'. [Adsorption specific surface area, porosity]. Moscow, 1984, 306 p. (in Russ.).

25. Pastor-Villegas J., Meneses Rodriguez J.M., Pastor-Valle J.F., Garcia Garcia M. J. Anal. Appl. Pyrolysis, 2007, vol. 80, pp. 507-514.

26. Rodriguez-Mirasol J., Bedia J., Cordero T. Separation Science and Technology, 2005, vol. 40, pp. 3113-3135.

27. Hara M., Yoshida T., Takagaki A., Takata T., Kondo J.N., Hayashi Sh., Domen K. Angew. Chem. Int. Ed., 2004, vol. 43, pp. 2955-2958.

28. Suganuma S., Nakajima K., Kitano M., Amaguchi D.Y., Kato H., Hayashi Sh., Hara M. Am. Chem. Soc., 2008, vol. 130, no. 38, pp. 12787-12793.

\footnotetext{
* Corresponding author.
} 
